Article

\title{
How Supplementary or Night-Interrupting Low-Intensity Blue Light Affects the Flower Induction in Chrysanthemum, a Qualitative Short-Day Plant
}

\author{
Yoo Gyeong Park ${ }^{1}(\mathbb{D})$ and Byoung Ryong Jeong ${ }^{1,2,3, *(D)}$ \\ 1 Institute of Agriculture and Life Science, Gyeongsang National University, Jinju 52828, Korea; \\ ygpark615@gmail.com \\ 2 Division of Applied Life Science (BK21 Plus Program), Graduate School, Gyeongsang National University, \\ Jinju 52828, Korea \\ 3 Research Institute of Life Science, Gyeongsang National University, Jinju 52828, Korea \\ * Correspondence: brjeong@gmail.com; Tel.: +82-010-6751-5489
}

Received: 19 October 2020; Accepted: 27 November 2020; Published: 2 December 2020

\begin{abstract}
This research examined the effects of the supplementary or night-interrupting (NI) blue (B) light supplied at a low intensity on the flowering, gene expression, and morphogenesis of chrysanthemum, a qualitative short-day plant. White (W) light-emitting diodes (LEDs) were used to provide light with a photosynthetic photon flux density (PPFD) of $180 \mu \mathrm{mol} \cdot \mathrm{m}^{-2} \cdot \mathrm{s}^{-1} \mathrm{during}$ the photoperiod to grow the plants in a plant factory. The control group was constructed with plants that were exposed to a 10-h short day (SD10) treatment without any blue light. The B light in this research was used for $4 \mathrm{~h}$ to either (1) extend the photoperiod for plants at the end of a 9-h short day (SD) treatment as the sole light source (SD9 + 4B), (2) provide night interruption (NI) to plants in the 13-h long-day (LD) treatment (LD13 + NI - 4B), (3) provide NI to plants in the 10-h SD treatment (SD10 + NI - 4B), or (4) supplement the W LEDs at the end of a 13-h LD treatment $(\mathrm{LD} 13+4 \mathrm{~B})$. Blue LEDs were used to provide the supplementary/NI light at $10 \mu \mathrm{mol} \cdot \mathrm{m}^{-2} \cdot \mathrm{s}^{-1} \mathrm{PPFD}$. The LD13 + NI - 4B treatment resulted in the greatest plant height, followed by LD13 + 4B. Plants in all treatments flowered. It is noteworthy that despite the fact that chrysanthemum is a qualitative SD plant, chrysanthemum plants flowered when grown in the LD13 + 4B and LD13 + NI - 4B treatments. Plants grown in the LD13 $+4 \mathrm{~B}$ had the greatest number of flowers. Plants grown in the LD13 + 4B treatment had the highest expression levels of the cryptochrome 1, phytochrome A, and phytochrome $B$ genes. The results of this study indicate that a 4 -h supplementation of $B$ light during the photoperiod increases flower bud formation and promotes flowering, and presents a possibility as an alternative method to using blackout curtains in LD seasons to practically induce flowering. The B light application methods to induce flowering in SD plants requires further research.
\end{abstract}

Keywords: blue LED; flower bud formation; number of flowers; photoperiod

\section{Introduction}

Plants adapt to the signals, such as the light quality, they perceive from the environment and accordingly modify their biological cycles [1]. Different types of photoreceptors, such as cryptochromes and phytochromes, enable plants to perceive changes in the light quality [2,3]. Throughout their lifecycle, the growth and development of plants are influenced by the photoreceptors. Photoreceptors monitor the light environment and also help plants time key developmental transitions, such as flowering and seed germination [4]. Phytochrome is a photoreceptor that primarily absorbs red (R) and far-red (Fr) lights, while cryptochrome is a photoreceptor that primarily absorbs ultraviolet-A (UV-A) and blue (B) lights, both of which help regulate flowering [5]. Multiple cryptochrome (CRY1 and 
CRY2) and phytochrome (PHYA, PHYB, PHYC, PHYD, and PHYE) varieties can exist, depending on the species $[6,7]$.

Light supplementation is often utilized for enhancing the quality of seedlings and rooted cuttings [8]. Photoperiod manipulation can reduce the production time and improve the overall crop quality to reduce production costs [9]. Light supplementation may take the form of supplementary light in a background of natural light, or additional light that extends the day length [8]. Night interruption (NI) interrupts a length of dark period with lighting, thus creating modified long-day (LD) conditions [10,11].

Studies have reported that B light negatively affects stem elongation and leads to a reduced leaf area [12-16]. Senger [17] found that blue light played a pivotal role in chloroplast development and formation, as well as the stomatal opening. It has been suggested that photoreceptors related to B light played a part in the flowering process [18,19]. Jeong et al. [20] reported that supplementary blue light at least in part promotes the elongation of stems and internodes without inhibiting the flower bud formation. In the short-day (SD) plant chrysanthemum, NI with B light did not effectively inhibit flowering, although B light is part of visible light [21,22]. Our previous study [11] split the traditional 4-h NI into two 2-h periods and shifted the NI light quality to examine how these changes affect the flowering and morphogenesis of chrysanthemum. They found out that B, Fr, R, and white (W) lights used in the first $2 \mathrm{~h}$ of the NI did not affect the morphogenesis nor flowering, while the same lights used in the last $2 \mathrm{~h}$ of the NI significantly impacted the morphogenesis and flowering. In addition, they discovered that flowering was induced in all NI treatments concluding with a blue light. Hence, we hypothesized that blue light at a low intensity supplemented to either LD or SD conditions may induce flowering in SD plants. Therefore, this study examined the effects of low-intensity (10 $\mu \mathrm{mol} \mathrm{m}{ }^{-2} \mathrm{~s}^{-1}$ PPFD) blue light used as supplementary or NI light on the flowering, gene expression, and morphogenesis in chrysanthemum 'Gaya Yellow' (a qualitative SD plant).

\section{Materials and Methods}

\subsection{Growth Conditions and Plant Materials}

Chrysanthemum (Dendranthema grandiflorum 'Gaya Yellow') spray-type cuttings were stuck in plug trays with 50 cells each filled with a commercial Tosilee Medium (Shinan Grow Company, Jinju, Korea). The cuttings were subsequently put on a glasshouse bench to root. The cuttings were relocated 12 days after they were stuck, when they have rooted, to a closed walk-in growth chamber that is $7700 \mathrm{~cm}$ by $2500 \mathrm{~cm}$ by $2695 \mathrm{~cm}$ in size. There, the plants were acclimatized to $20 \pm 1{ }^{\circ} \mathrm{C}$, $60 \% \pm 10 \% \mathrm{RH}$, and $140 \mu \mathrm{mol} \cdot \mathrm{m}^{-2} \cdot \mathrm{s}^{-1}$ PPFD supplied with F48T12-CW-VHO fluorescent lamps (Philips Co., Ltd., Eindhoven, The Netherlands). The closed walk-in growth chamber was constructed such that numerous uniformly distributed holes allowed conditioned air to blow horizontally into the growing spaces. $\mathrm{CO}_{2}$ was supplemented from a compressed gas tank to maintain an atmospheric concentration of $350 \pm 50 \mu \mathrm{mol} \cdot \mathrm{mol}^{-1}$. The plants, after 11 days of acclimatization (the 16-h LD) in the growth chamber, were approximately $7.0 \mathrm{~cm}$ in height and were subjected to the photoperiodic light treatments. After being planted, the chrysanthemums were fertigated once a day (from 9:00 a.m. to 10:0 a.m.) throughout the experiment with a greenhouse multipurpose nutrient solution [11]. A 3-replication randomized complete block design was employed with a total of 6 plants for each treatment, with 2 plants in each replication. Within a controlled environment, the photoperiodic light treatments were randomly located in between replications to minimize the effects of the light treatment positioning.

\subsection{Photoperiodic Light Treatments}

Plants were grown with light at an intensity of $180 \mu \mathrm{mol} \mathrm{m}{ }^{-2} \mathrm{~s}^{-1}$ PPFD provided by white MEF50120 LEDs (More Electronics Co. Ltd., Changwon, Korea) (Figure 1A). The different photoperiods used in this experiment, as well as the lighted period during the NI (referred to as 'photoperiod' hereafter) were as follows: B light with a wavelength of $450 \mathrm{~nm}$ was used for $4 \mathrm{~h}$ to either (1) extend 
the photoperiod at the end of a 9-h SD as the sole light source (SD9 + 4B), (2) provide NI following the 13-h LD (LD13 + NI - 4B), (3) provide NI after the 10-h SD (SD10 + NI - 4B), or (4) supplement $\mathrm{W}$ LEDs at the end of a 13-h LD (LD13 + 4B) (Figures 1B and 2). The control was constructed by exposing the plants to a 10-h short-day treatment (SD10) without B light. B light at an intensity of $10 \pm 3 \mu \mathrm{mol} \cdot \mathrm{m}^{-2} \cdot \mathrm{s}^{-1}$ PPFD was provided by LEDs for the photoperiodic light treatments. A HD2102.1 digital photometer (Delta OHM, Padova, Italy) measured the average PPFD $20 \mathrm{~cm}$ above the bench top, for each light treatment. The lighting was adjusted such that the same PPFD levels were provided to the plants regardless of the light treatment. A USB 2000 Fiber Optic Spectrometer (Ocean Optics Inc., Dunedin, FL, USA; detects wavelengths between 200 to $1000 \mathrm{~nm}$ ) scanned the spectral distribution in 1-nm wavelength intervals $25 \mathrm{~cm}$ above the bench top.

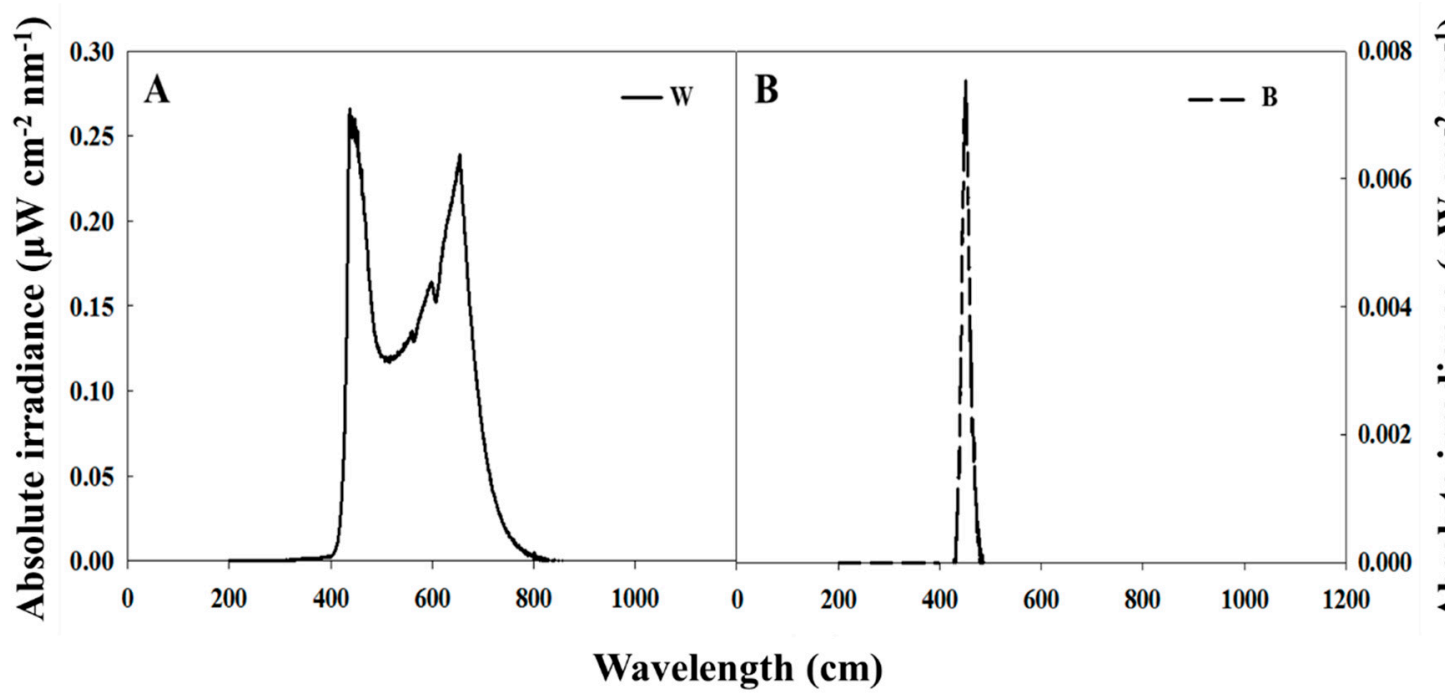

Figure 1. The spectral distribution of lights used in this experiment: daily $W$ light provided by white LEDs (A) and B light from blue LEDs used as the supplementary and night-interrupting light (B).

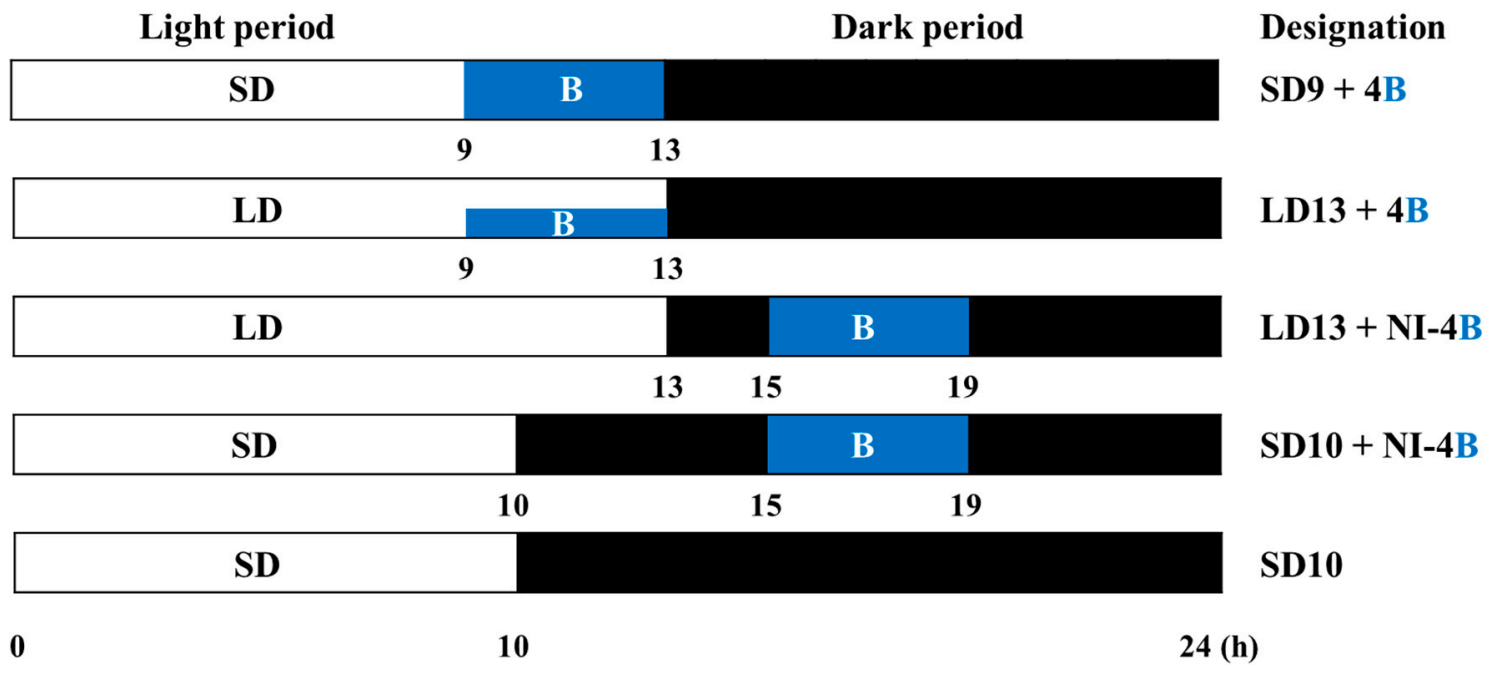

Figure 2. Supplementary and night-interrupting blue (B) light schemes employed in this study. B light was used for $4 \mathrm{~h}$ to either (1) extend the photoperiod at the end of a 9-h SD as the sole light source (SD9 + 4B), (2) provide NI following a 13-h LD (LD13 + NI - 4B), (3) provide NI after a 10-h SD $(\mathrm{SD} 10+\mathrm{NI}-4 \mathrm{~B})$, or (4) supplement the W light at the end of a 13-h LD (LD13 + 4B). Plants in the control were grown with a 10- hour SD treatment (SD10) without any B light. 


\subsection{Data Collection and Statistical Analysis}

The dry mass, number of leaves per plant, number of nodes per plant, number of flowers per plant, plant height, leaf area, chlorophyll content, percent flowering, days of treatment needed to visible flower bud or days to visible buds (DVB), flower width, and photoreceptor gene expressions were measured after 41 days of the photoperiodic light treatments. All leaves with a length greater than $1 \mathrm{~cm}$ in were counted to determine the number of leaves per plant. Divided samples of the shoot and root were dried at $70^{\circ} \mathrm{C}$ for $72 \mathrm{~h}$ in a Venticell-222 drying oven (MMM Medcenter Einrichtungen $\mathrm{GmbH} .$, Munich, Germany) before the dry mass measurements were taken with an EW 220-3NM electronic scale (Kern and Sohn GmbH., Balingen, Germany). Leaf area measurements were taken with a LI-3000 leaf area meter (LI-COR Inc., Lincoln, NE, USA). The chlorophyll concentration was estimated from 10-mg samples of fresh, young, and fully developed leaves. Chlorophyll was extracted with $80 \%$ acetone at $4{ }^{\circ} \mathrm{C}$. A Biochrom Libra S22 spectrophotometer (Biochrom Co. Ltd., Holliston, MA, USA) measured the absorbance of the supernatant at 645 and $663 \mathrm{~nm}$, after the extracted chlorophyll was centrifuged at $3000 \mathrm{rpm}$. Calculations were performed according to the method described by Dere et al. [23]. The statistical analysis was performed with the SAS 9.1 software (SAS Institute Inc., Cary, NC, USA). An analysis of variance (ANOVA) and Tukey's multiple range test were performed with the results of this study. SigmaPlot 12.0 (Systat Software Inc., San Jose, CA, USA) was used for graphing.

\subsection{Total RNA Isolation, cDNA Synthesis, and Real-Time Polymerase Chain Reaction (PCR) of Selected Genes}

After 20 days of the photoperiodic light treatments, plants started displaying visible flower buds and the most recently matured 10 leaves per plant were collected for total RNA extraction. The latest leaf to be matured was collected an hour after the daily photoperiodic treatments began, at 9:00 a.m. This collection time was chosen because the photosynthetic rates are high at this time of the day. Equal amounts of cDNA using primers of cryptochrome 1 (CRY1), phytochrome A (PHYA), and phytochrome $B(P H Y B)$, whose sequences are shown in Table 1 , were used to perform the independent PCRs. As actin is frequently used to normalize molecular expression studies, it was used as an internal control. The $2^{-\Delta \Delta C t}$ method [24] was used to determine the relative expression levels of each gene. At each sampling date, the individual gene expression levels in the plants grown with the light treatments were divided by the mean gene expression levels for plants in the control (SD10). The total RNA isolation and real-time quantitative PCR analysis of the selected genes were performed according to the method described in Park et al. [11].

Table 1. The primers used to quantify the gene expression levels.

\begin{tabular}{cccc}
\hline Gene & Accession no. & Forward Primer & Reverse Primer \\
\hline CRY1 & NM_116961 & 5'-CGTAAGGGATCACCGAGTAAAG-3' & 5'-CTTTTAGGTGGGAGTTGTGGAG-3' \\
PHYA & EU915082 & 5'-GACAGTGTCAGGCTTCAACAAG-3' & 5'-ACCACCAGTGTGTGTTATCCTG-3' \\
PHYB & NM_127435 & 5'-GTGCTAGGGAGATTACGCTTTC-3' & 5'-CCAGCTTCTGAGACTGAACAGA-3' \\
Actin & AB205087 & 5'-CGTTTGGATCTTGCTGGTCG-3' & 5'-CAGGACATCTGAAACGCTCA-3' \\
\hline
\end{tabular}

\section{Results}

\subsection{Morphogenesis}

It was observed that the supplementary and night-interrupting blue light increased the plant heights in this study (Figure 3A). Plants grown in LD13 + NI - 4B had the greatest height (Figure 3A), where it was $22 \%$ greater than that of plants grown in SD10. Additionally, it was observed that even plants in SD9 $+4 \mathrm{~B}$ had a greater mean height than those in SD10. 

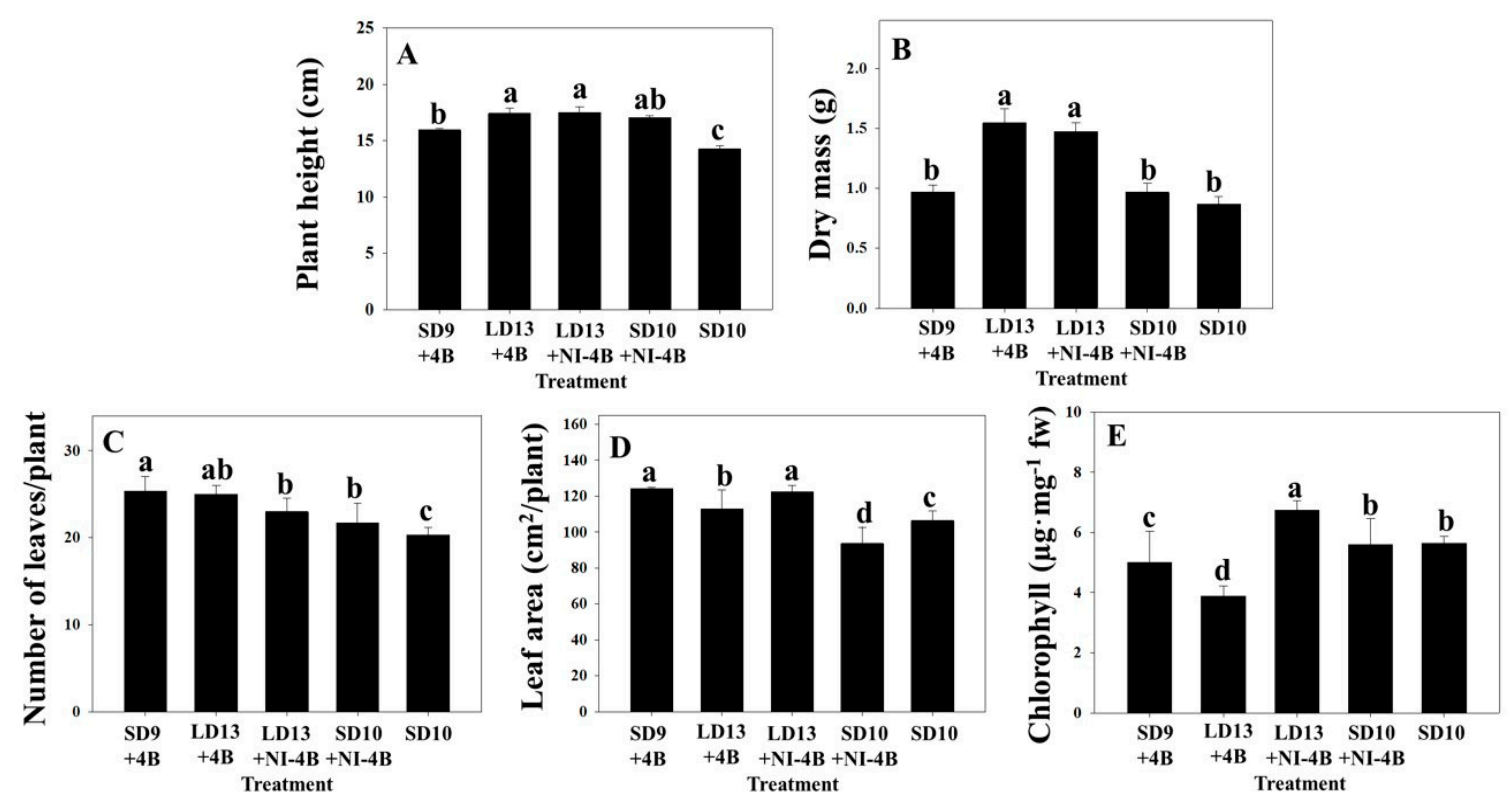

Figure 3. The effects of the supplementary and night-interrupting B light on the plant height (A), dry mass (B), number of leaves per plant (C), leaf area per plant (D), and chlorophyll levels (E) in D. grandiflorum 'Gaya Yellow'. The control was constructed by exposing plants to a 10-h SD treatment (SD10) without any B light. Data are the mean \pm S.E of the 3 biological replicates. Means accompanied by different letters significantly differ $(p<0.05)$ according to Tukey's studentized range test at a $5 \%$ significance level.

The dry mass of plants grown under all photoperiodic treatments was greater compared to that of the plants in the SD10 control (Figure 3B). Increasing the photoperiod, as with LD13 $+4 \mathrm{~B}$ and LD13 + NI - 4B, significantly increased the dry mass of the plants in this study. The other treatments, SD9 $+4 \mathrm{~B}$ and SD10 + NI $-4 \mathrm{~B}$, were not as effective as the LD treatments in increasing the dry mass (Figure 3B).

Plants in SD9 + 4B had the greatest number of leaves per plant while those in SD10 had the lowest number of leaves per plant (Figure $3 \mathrm{C}$ ). The average leaf area was the greatest for plants in $\mathrm{LD} 13+\mathrm{NI}-4 \mathrm{~B}$ and the smallest for plants in SD10 + NI $-4 \mathrm{~B}$ (Figure 3D). The leaf area per plant was $12 \%$ for plants in SD10 + NI - 4B when compared to that for plants in SD10 (Figure 3D). Furthermore, all B light treatments except for SD10 + NI $-4 \mathrm{~B}$ increased the leaf area compared to the control (Figure 3D). The chlorophyll levels were the lowest for plants in LD13 $+4 \mathrm{~B}$ and the highest for plants in LD13 + NI - 4B (Figure 3E). Plants in LD13 + 4B had 32\% lower chlorophyll contents than plants in SD10 did (Figure 3E).

\subsection{Flowering and Gene Expression}

The flowering percentage of plants was 100\% in all treatments (Table 2 and Figure 4). The fastest flowering induction was observed for plants in the control (SD10). It is noteworthy that plants in $\mathrm{LD} 13+4 \mathrm{~B}$ and $\mathrm{LD} 13+\mathrm{NI}-4 \mathrm{~B}$ flowered, despite the fact that chrysanthemum is a qualitative SD plant (Table 2 and Figure 4). 
Table 2. The effects of the supplementary and night-interrupting $10 \mu \mathrm{mol} \cdot \mathrm{m}^{-2} \cdot \mathrm{s}^{-1}$ PPFD B light on the flowering characteristics of chrysanthemum (D. grandiflorum 'Gaya Yellow'), after 41 days of exposure to the photoperiodic light treatments.

\begin{tabular}{ccccc}
\hline Treatment $^{\mathbf{z}}$ & Flowering (\%) & DVB $^{\mathbf{y}}$ (Day) & No. of Flowers/Plant & Flower width (cm) \\
\hline SD9 + 4B & 100 & $17.7 \mathrm{c}^{\mathrm{x}}$ & $11.0 \mathrm{c}$ & $2.6 \mathrm{~b}$ \\
LD13 + 4B & 100 & $22.5 \mathrm{~b}$ & $21.3 \mathrm{a}$ & $0.7 \mathrm{c}$ \\
LD13 + NI - 4B & 100 & $28.7 \mathrm{a}$ & $15.3 \mathrm{~b}$ & $0.5 \mathrm{~d}$ \\
SD10 + NI - 4B & 100 & $18.0 \mathrm{c}$ & $15.0 \mathrm{~b}$ & $2.8 \mathrm{a}$ \\
SD10 & 100 & $17.5 \mathrm{c}$ & $11.0 \mathrm{c}$ & $2.9 \mathrm{a}$ \\
F-test & & $* * *$ & $* * *$ & $* *$ \\
\hline
\end{tabular}

${ }^{\mathrm{z}}$ See Figure 2 for details on the photoperiodic treatments with B light. ${ }^{\mathrm{y}}$ Days of treatment to visible flower bud or days to visible buds. ${ }^{x}$ Mean separation within columns by Duncan's multiple range test at a $5 \%$ level. ${ }^{* * *}$ : Significant at $p \leq 0.001$.
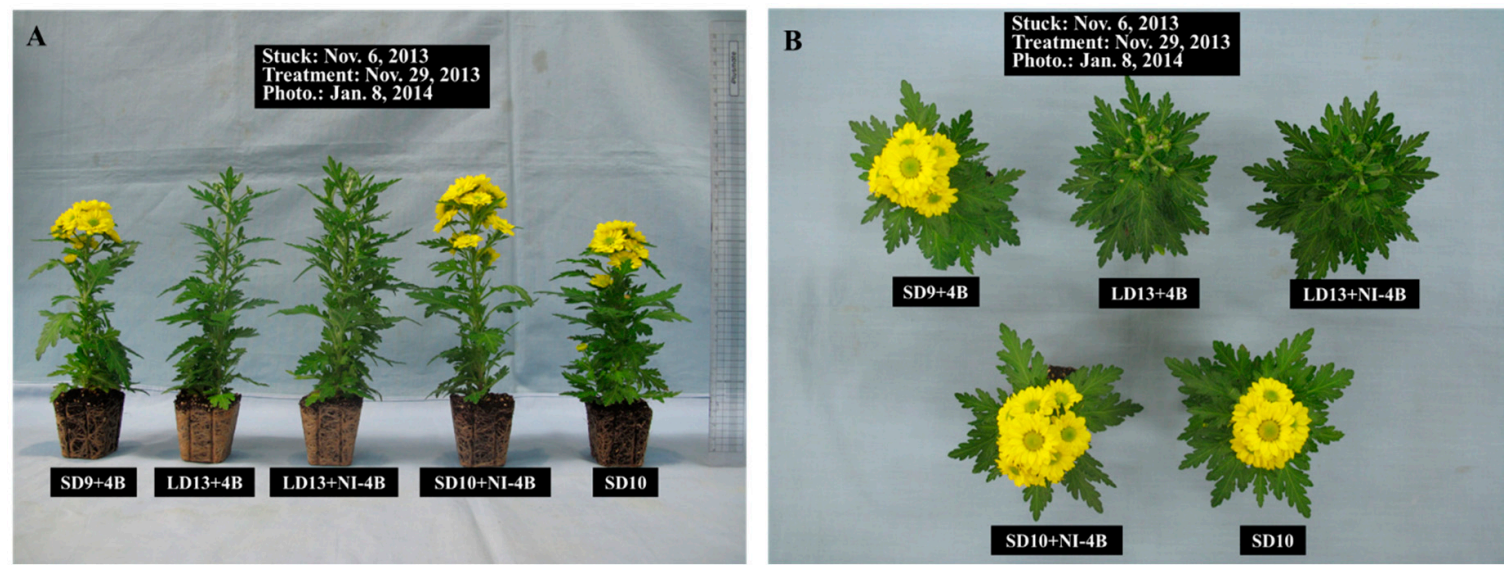

Figure 4. The effects of the supplementary and night-interrupting $10 \mu \mathrm{mol} \cdot \mathrm{m}^{-2} \cdot \mathrm{s}^{-1} \mathrm{PPFD}$ B light on the flowering of chrysanthemum (D. grandiflorum 'Gaya Yellow'), after 41 days of exposure to the photoperiodic light treatments: side view (A) and top view (B) (see Figure 2 for details on the photoperiodic treatments with B light).

Plants in SD10 had the smallest DVB whereas plants in LD13 + NI - 4B had the greatest DVB (Table 2). The DVB was observed to increase as the photoperiod increased (Table 2). The DVB of plants in LD13 + 4B was smaller than those of plants in LD13 + NI - 4B. Interestingly, plants in LD13 + 4B had 93\% more flowers per plant compared to plants in the SD10 control. Plants in the SD10 control and SD9 + 4B had the lowest number of flowers (Table 2). Plants in the SD10 control had the greatest flower width (Table 2).

The photoreceptor gene expression (PHYA, PHYB, and CRY1) in response to the B light was also analyzed (Figure 5). Plants in LD13 + 4B had the greatest expression levels of PHYA and PHYB, followed by plants in SD10 + NI - 4B (Figure 5). PHYA had the lowest expression levels in plants in LD13 + NI - 4B (Figure 5). PHYB was the least expressed in plants in LD13 + NI - 4B (Figure 5). Plants in LD13 + NI - 4B had significantly higher CRY1 expression levels compared to plants in the other treatments (Figure 5). CRY1 was the least expressed in plants in LD13 + 4B (Figure 5). 

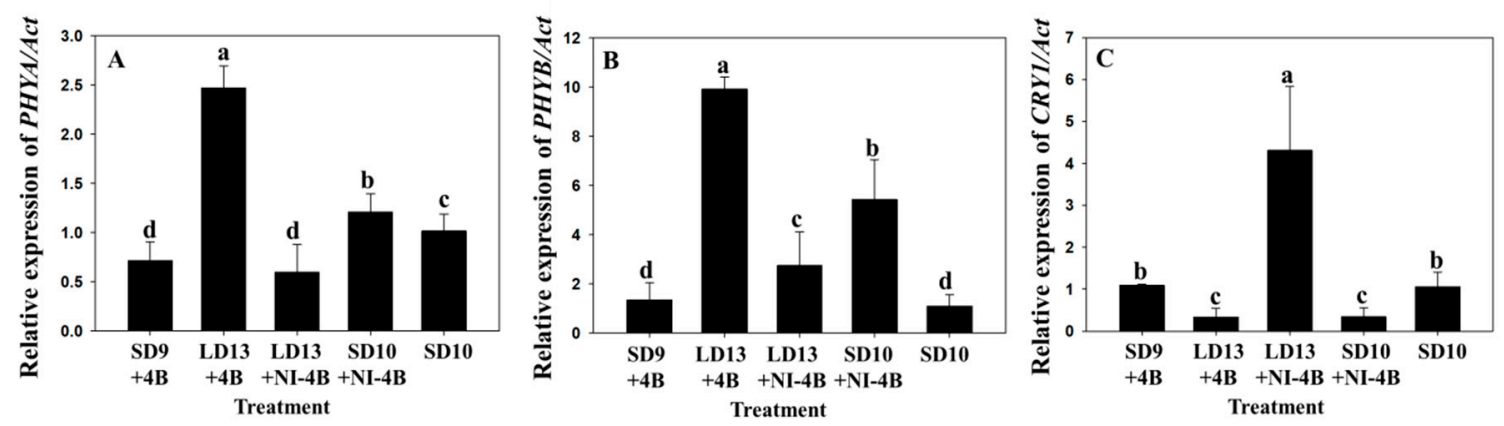

Figure 5. The effects of the supplementary and night-interrupting $10 \mu \mathrm{mol} \cdot \mathrm{m}^{-2} \cdot \mathrm{s}^{-1} \mathrm{PPFD} B$ light on the relative gene expression levels of) D. grandiflorum 'Gaya Yellow' determined by real-time PCR of PHYA (A), PHYB (B), and CRY1 (C). (Details of the NI light qualities are presented in Figure 2). At each sampling date, the individual gene expression levels for the plants in the photoperiodic light treatments were divided by the mean gene expression level for plants in the SD10 control. The data are presented as the mean \pm S.E of the 3 biological replicates. Means accompanied by different letters indicate significant differences $(p<0.05)$, according to Tukey's studentized range test at a 5\% significance level.

\section{Discussion}

\subsection{Plant Height}

Different studies have observed that blue light acts to limit the elongation of the petiole, stem, and hypocotyl in various horticultural species, such as chrysanthemum, lettuce, pepper, and soybean [25-32]. Normally, increasing blue light decreases the stem length to a maximum threshold level [32]. Schuerger et al. [30] observed that blue light for $12 \mathrm{~h}$ a day plays a role in changing the stem anatomy, inhibiting the growth, and determining the morphogenetic characteristics of pepper plants. Furthermore, Khattak and Pearson [33] found that B light during the photoperiod in low-light environments resulted in reduced plant heights. Cryptochromes are also known to influence the stem elongation, and various of plants exhibit suppressed shoot elongation in response to B light in a 12-h day [26]. However, these photomorphogenic responses are different for different species. Previous studies used B light during the photoperiod to control the morphogenesis, while the current study used B light as a supplement or for NI to control morphogenesis and flowering.

All the photoperiodic light treatments considered in this study resulted in greater plant heights than that observed in the SD10 control (Figure 3A). This indicates that blue light may be used in the production of cut chrysanthemum flowers, as longer stems are considered to be of better quality. Kong et al. [34] stated that the increased elongation growth of plants in response to B light is linked to lower phytochrome activity, and is a shade-avoidance response, where different species have different sensitivities. These results agree with those of Jeong et al. [20], where it was found that an extended photoperiod with blue light promoted stem elongation of chrysanthemum. Longer photoperiods are known to be associated with the presence of higher gibberellin levels, which enhance stem elongation in chrysanthemums [20,35]. In many species, including salvia and marigold, B light was more effective than R light in increasing the shoot elongation [36]. Muleo and Morini [37] reported that internode extension on the stem leader in apple was inhibited by B LED, which determined the lowest values among all the light qualities tested. The differing responses of different plants to B light indicates that a species' responses to a specific light quality cannot necessarily be predicted on the basis of responses of other species.

\subsection{Dry Mass and Leaf Growth}

In this study, plants in LD13 + 4B and LD13 + NI $-4 \mathrm{~B}$ had greater shoot and root dry masses compared to plants in the SD10 control (Figure 3B). These results indicate that a prolonged photoperiod contributed to the dry matter production. Moreover, B light supplementation increases 
the photosynthetic carbon assimilation and may also allow greenhouse crops to accumulate a greater biomass [38].

Plants in all the photoperiodic light treatments had a higher number of leaves per plant compared to plants in the control, and plants in SD9 + 4B had the greatest number of leaves (Figure 3C). Plants in SD10 + NI-4B had a smaller mean leaf area than plants in the SD10 control did (Figure 3D), resulting from shorter leaf lengths and widths (data not shown). All other treatments with B light led to a greater leaf area than that of plants in the SD10 control. Wang et al. [39] reported similar results, where light treatments with weak $50 \mu \mathrm{mol} \cdot \mathrm{m}^{-2} \cdot \mathrm{s}^{-1}$ PPFD B light lead to increases in the leaf area. Honecke et al. [26] proposed that B light is required during the photoperiod for the normal growth of lettuce seedlings grown under R LEDs; if the B light level was low, long, narrow leaves developed. Iacona and Muleo [40] reported that total leaf area per plant in cherry rootstock 'Colt' was significantly greater in B LED-exposed plants than other treatments. However, these photomorphogenic responses are specific to the particular species. Dougher and Bugbee [41] reported that increasing the B light proportion resulted in decreasing leaf area in soybean, while in lettuce, increasing the B light proportion resulted in increasing the leaf area. Eskins [42] observed that the Arabidopsis thaliana leaf area was negatively correlated with the B light proportion, as a high-intensity B light irradiance corresponded to the development of small leaves.

Gang et al. [43] observed that the chlorophyll levels increased as plants transitioned from the vegetative to the reproductive growth, and decreased during maturation. Correspondingly, the lower chlorophyll content of plants in LD13 $+4 \mathrm{~B}$ compared to that of plants in the other treatments in this study (Figure 3E) may be due to the continued maturation after the plants transition from the vegetative to reproductive growth.

\subsection{Expression of Genes Related to the Morphogenesis and Flowering}

The expression levels of PHYA and PHYB were the highest for plants in LD13 + 4B, and the expression level of $C R Y 1$ was the greatest for plants in LD13 + NI - 4B. Plants in these two treatments were also the tallest. It has been reported that cryptochromes and phytochromes affect the height of chrysanthemums [33]. In Arabidopsis, high PHYB levels can increase the expression of AtGAox2, which controls the synthesis of gibberellins (GAs) [35]. Furthermore, it has been verified that both phytochromes and cryptochromes play a part in the regulation of the plant hormone GA levels [35,44]. Thus, it is speculated that the high expression levels of $P H Y A, P H Y B$, and CRY1 found in plants grown in LD13 + 4B and LD13 + NI - 4B may promote the synthesis of GAs and eventually result in greater plant heights.

It is well known that photoreceptors related to B light were involved in the flowering process $[18,20]$. The CRY1 and CRY2 both mediate the flowering promotion by B light [45]. PHYA mediates the flowering promotion by Fr light, and $P H Y B$ mediates the flowering inhibition by $\mathrm{R}$ light in Arabidopsis [46-48]. Although $P H Y A$ and $P H Y B$ are $\mathrm{R}$ light receptors, it has also been shown that they also function under B light in Arabidopsis [49], and it has been proven that either PHYA or PHYB, as well as cryptochromes, were required for responses to $B$ light $[24,46,50]$. In this study, the number of flowers per plant was shown to increase with the B light treatments. This may be attributed to the high CRY1 expression levels. Similarly, Park et al. [11] reported that a greater number of flowers per plant was observed with light shifting from B during the NI, which may be attributed to a high light energy induction as well as shade avoidance responses, a behavior where plants evade darkness by lengthening the internodes. In rice, NI with B light delayed the flowering time, but this delay was not reproduced in the PHYB-1 mutant [51], which means $P H Y B$ is a negative regulator for the flowering time. It was also observed that while chrysanthemum is a qualitative SD plant, those in the LD13 + 4B and LD13 $+\mathrm{NI}-4 \mathrm{~B}$ treatments still flowered. This indicates that high PHYA and CRY1 expression levels may induce flowering. However, further research is necessary to verify this speculation.

In summary, B light resulted in a greater height and promoted the flowering in chrysanthemum. The results of this study illustrate that a 4-h B light supplementation during the photoperiod promoted 
flowering and increased the number of flower buds formed. Hence, B light supplementation may be an optimal technique to induce flowering, and can be practically applied to commercial cultivation of SD plants. This study suggests that $B$ light supplementation is an alternative practical technique to induce flowering in SD plants to using blackout curtains during LD seasons. Further research is still needed to optimize B light supplementation techniques for flowering induction of SD plants.

Author Contributions: B.R.J. and Y.G.P. conceived and designed the experiments; Y.G.P. performed the experiments; B.R.J. and Y.G.P. analyzed the data; B.R.J. and Y.G.P. contributed reagents/materials/analysis tools; B.R.J. and Y.G.P. wrote the paper. All authors have read and agreed to the published version of the manuscript.

Funding: The APC was funded by Gyeongsagn National University.

Acknowledgments: The authors express their gratitude to Sowbiya Muneer, Prabhakaran Soundararajan, and Young Don Chin for their assistance.

Conflicts of Interest: The authors declare no conflict of interest.

\section{References}

1. Demotes-Mainard, S.; Péron, T.; Corot, A.; Bertheloot, J.; Gourrierec, J.G.-L.; Pelleschi-Travier, S.; Crespel, L.; Morel, P.; Huché-Thélier, L.; Boumaza, R.; et al. Plant responses to red and far-red lights, applications in horticulture. Environ. Exp. Bot. 2016, 121, 4-21. [CrossRef]

2. Galvāo, V.C.; Fankhauser, C. Sensing the light environment in plants: Photoreceptors and early signaling steps. Curr. Opin. Neurobiol. 2015, 34, 46-53. [CrossRef]

3. Huché-Thélier, L.; Crespel, L.; Gourrierec, J.G.-L.; Morel, P.; Sakr, S.; LeDuc, N. Light signaling and plant responses to blue and UV radiations-Perspectives for applications in horticulture. Environ. Exp. Bot. 2016, 121, 22-38. [CrossRef]

4. Kami, C.; Lorrain, S.; Hornitschek, P.; Fankhauser, C. Light-regulated plant growth and development. Curr. Top. Dev. Biol. 2010, 91, 29-66. [CrossRef]

5. Cashmore, A.R.; Jarillo, J.A.; Wu, Y.-J.; Liu, D. Cryptochromes: Blue light receptors for plants and animals. Science 1999, 284, 760-765. [CrossRef]

6. Clack, T.; Mathews, S.; Sharrock, R.A. The phytochrome apoprotein family inArabidopsis is encoded by five genes: The sequences and expression of PHYD and PHYE. Plant Mol. Biol. 1994, 25, 413-427. [CrossRef]

7. Sharrock, R.A.; Quail, P.H. Novel phytochrome sequences in Arabidopsis thaliana: Structure, evolution, and differential expression of a plant regulatory photoreceptor family. Genes Dev. 1989, 3, 1745-1757. [CrossRef]

8. Wang, K.; Weng, Q.; Huang, L.; Wang, K.; Deng, J.; Jiang, R.; Ye, Z.; Gan, M. A new source of multi-spectral high spatial resolution night-time light imagery-JL1-3B. Remote Sens. Environ. 2018, 215, 300-312. [CrossRef]

9. Runkle, E.S.; Heins, R. Manipulating the light environment to control flowering and morphogenesis of herbaceous plants. Acta Hortic. 2006, 711, 51-60. [CrossRef]

10. Yamada, A.; Tanigawa, T.; Suyama, T.; Matsuno, T.; Kunitake, T. Night break treatment using different light sources promotes or delays growth and flowering of Eustoma grandiflorum (Raf.) Shinn. J. Jpn. Soc. Hortic. Sci. 2008, 77, 69-74. [CrossRef]

11. Park, Y.G.; Muneer, S.; Jeong, B.R. Morphogenesis, flowering, and gene expression of Dendranthema grandiflorum in response to shift in light quality of night interruption. Int. J. Mol. Sci. 2015, 16, 16497-16513. [CrossRef]

12. Appelgren, M. Effects of light quality on stem elongation of Pelargonium in vitro. Sci. Hortic. 1991, 45, 345-351. [CrossRef]

13. Dougher, T.A.; Bugbee, B. Long-term blue light effects on the histology of lettuce and soybean leaves and stems. J. Am. Soc. Hortic. Sci. 2004, 129, 467-472. [CrossRef]

14. Folta, K.M.; Lieg, E.J.; Durham, T.; Spalding, E.P. Primary inhibition of hypocotyl growth and phototropism depend differently on phototropin-mediated increases in cytoplasmic calcium induced by blue light. Plant Physiol. 2003, 133, 1464-1470. [CrossRef] [PubMed]

15. Kubota, C.; Rajapakse, N.C.; Young, R.E. Carbohydrate status and transplant quality of micropropagated broccoli plantlets stored under different light environments. Postharvest Biol. Technol. 1997, 12, 165-173. [CrossRef] 
16. Rajapakse, N.C.; McMahon, M.J.; Kelly, J.W. End of day far-red light reverses height reduction of chrysanthemum induced by CuSO4 spectral filters. Sci. Hortic. 1993, 53, 249-259. [CrossRef]

17. Senger, H. The effect of blue light on plants and microorganisms. Photochem. Photobiol. 1982, 35, 911-920. [CrossRef]

18. Fankhauser, C.; Ulm, R. Light-regulated interactions with SPA proteins underlie cryptochrome-mediated gene expression. Genes Dev. 2011, 25, 1004-1009. [CrossRef]

19. Hirose, F.; Shinomura, T.; Tanabata, T.; Shimada, H.; Takano, M. Involvement of rice cryptochromes in de-etiolation responses and flowering. Plant Cell Physiol. 2006, 47, 915-925. [CrossRef]

20. Jeong, S.W.; Hogewoning, S.W.; Van Ieperen, W. Responses of supplemental blue light on flowering and stem extension growth of cut chrysanthemum. Sci. Hortic. 2014, 165, 69-74. [CrossRef]

21. Higuchi, Y.; Sumitomo, K.; Oda, A.; Shimizu, H.; Hisamatsu, T. Day light quality affects the night-break response in the short-day plant chrysanthemum, suggesting differential phytochrome-mediated regulation of flowering. J. Plant Physiol. 2012, 169, 1789-1796. [CrossRef] [PubMed]

22. Park, Y.G.; Jeong, B.R. Night interruption light quality changes morphogenesis, flowering, and gene expression in Dendranthema grandiflorum. Hortic. Environ. Biotechnol. 2019, 60, 167-173. [CrossRef]

23. Dere, S.; Gunes, T.; Sivaci, R. Spectrophotometric determination of chlorophyll—a, b and total carotenoid contents of some algae species using different solvents. Turk. J. Bot. 1998, 22, 13-17.

24. Livak, K.J.; Schmittgen, T.D. Analysis of relative gene expression data using real-time quantitative PCR and the $2^{-\Delta \Delta C t}$ method. Methods 2001, 25, 402-408. [CrossRef] [PubMed]

25. Brown, C.S.; Schuerger, A.C.; Sager, J.C. Growth and photomorphogenesis of pepper plants under red light-emitting diodes with supplemental blue or far-red lighting. J. Am. Soc. Hortic. Sci. 1995, 120, 808-813. [CrossRef]

26. Hoenecke, M.; Bula, R.; Tibbitts, T. Importance of 'blue' photon levels for lettuce seedlings grown under red-light-emitting diodes. HortScience 1992, 27, 427-430. [CrossRef]

27. Holmes, M.G. Action spectra for changes in the "high irradiance reaction" in hypocotyls of Sinapis alba L. Planta 1981, 153, 267-272. [CrossRef]

28. Kim, S.-J.; Hahn, E.-J.; Heo, J.-W.; Ali, M.B. Effects of LEDs on net photosynthetic rate, growth and leaf stomata of chrysanthemum plantlets in vitro. Sci. Hortic. 2004, 101, 143-151. [CrossRef]

29. Oyaert, E.; Volckaert, E.; DeBergh, P. Growth of chrysanthemum under coloured plastic films with different light qualities and quantities. Sci. Hortic. 1999, 79, 195-205. [CrossRef]

30. Schuerger, A.C.; Brown, C.S.; Stryjewski, E.C. Anatomical features of pepper plants (Capsicum annuum L.) grown under red light-emitting diodes supplemented with blue or far-red light. Ann. Bot. 1997, 79, $273-282$. [CrossRef]

31. Shimizu, H.; Ma, Z.; Tazawa, S.; Douzono, M.; Runkle, E.S.; Heins, R. Blue light inhibits stem elongation of chrysanthemum. Acta Hortic. 2006, 711, 363-368. [CrossRef]

32. Wheeler, R.M.; Mackowiak, C.L.; Sager, J.C. Soybean stem growth under high-pressure sodium with supplemental blue lighting. Agron. J. 1991, 83, 903-906. [CrossRef]

33. Khattak, A.M.; Pearson, S. Spectral filters and temperature effects on the growth and development of chrysanthemums under low light integral. Plant Growth Regul. 2006, 49, 61-68. [CrossRef]

34. Kong, Y.; Stasiak, M.; Dixon, M.A.; Zheng, Y. Blue light associated with low phytochrome activity can promote elongation growth as shade-avoidance response: A comparison with red light in four bedding plant species. Environ. Exp. Bot. 2018, 155, 345-359. [CrossRef]

35. Xu, Y.L.; Gage, D.A.; Zeevaart, J. Gibberellins and stem growth in Arabidopsis thaliana. Effects of photoperiod on expression of the GA4 and GA5 loci. Plant Physiol. 1997, 114, 1471-1476. [CrossRef]

36. Heo, J.; Lee, C.; Chakrabarty, D.; Paek, K.-Y. Growth responses of marigold and salvia bedding plants as affected by monochromic or mixture radiation provided by a light-emitting diode (LED). Plant Growth Regul. 2002, 38, 225-230. [CrossRef]

37. Muleo, R.; Morini, S. Light quality regulates shoot cluster growth and development of MM106 apple genotype in in vitro culture. Sci. Hortic. 2006, 108, 364-370. [CrossRef]

38. Hao, X.; Papadopoulos, A.P. Effects of supplemental lighting and cover materials on growth, photosynthesis, biomass partitioning, early yield and quality of greenhouse cucumber. Sci. Hortic. 1999, 80, 1-18. [CrossRef] 
39. Wang, X.Y.; Xu, X.M.; Cui, J. The importance of blue light for leaf area expansion, development of photosynthetic apparatus, and chloroplast ultrastructure of Cucumis sativus grown under weak light. Photosynthetica 2015, 53, 213-222. [CrossRef]

40. Iacona, C.; Muleo, R. Light quality affects in vitro adventitious rooting and ex vitro performance of cherry rootstock Colt. Sci. Hortic. 2010, 125, 630-636. [CrossRef]

41. Dougher, T.A.; Bugbee, B.G. Difference in response of wheat, soybean and lettuce to reduced blue radiation. J. Photochem. Photobiol. 2011, 73, 199-207. [CrossRef]

42. Eskins, K. Light-quality effects on Arabidopsis development. Red, blue and far-red regulation and morphology. Physiol. Plant. 1992, 86, 439-444. [CrossRef]

43. Gang, Z.; Yu, T.; Banghua, Y.; Xiaolei, L. A study on the relationship between the chlorophyll content and the yield of plant of tartary buckwheat. In Proceedings of the 5th International Symposium on Buckwheat, Taiyuan, China, 20-26 August 1992; pp. 122-126.

44. Zhao, X.-Y.; Yu, X.-H.; Liu, X.; Lin, C. Light regulation of gibberellins metabolism in seedling development. J. Integr. Plant Biol. 2007, 49, 21-27. [CrossRef]

45. Mockler, T.; Yang, H.; Yu, X.; Parikh, D.; Cheng, Y.-C.; Dolan, S.; Lin, C. Regulation of photoperiodic flowering by Arabidopsis photoreceptors. Proc. Natl. Acad. Sci. USA 2003, 100, 2140-2145. [CrossRef] [PubMed]

46. Johnson, E.; Bradley, M.; Harberd, N.P.; Whitelam, G.C. Photoresponses of light-grown phyA mutants of Arabidopsis (Phytochrome A is required for the perception of daylength extensions). Plant Physiol. 1994, 105, 141-149. [CrossRef]

47. Mockler, T.C.; Guo, H.; Yang, H.; Lin, D.C. Antagonistic actions of Arabidopsis cryptochromes and phytochrome $\mathrm{B}$ in the regulation of floral induction. Development 1999, 126, 2073-2082.

48. Franklin, K.A.; Praekelt, U.; Stoddart, W.M.; Billingham, O.E.; Halliday, K.J.; Whitelam, G.C. Phytochromes B, D, and E act redundantly to control multiple physiological responses in Arabidopsis. Plant Physiol. 2003, 131, 1340-1346. [CrossRef]

49. Shinomura, T.; Nagatani, A.; Hanzawa, H.; Kubota, M.; Watanabe, M.; Furuya, M. Action spectra for phytochrome A- and B-specific photoinduction of seed germination in Arabidopsis thaliana. Proc. Natl. Acad. Sci. USA 1996, 93, 8129-8133. [CrossRef]

50. Usami, T.; Mochizuki, N.; Kondo, M.; Nishimura, M.; Nagatani, A. Cryptochromes and phytochromes synergistically regulate Arabidopsis root greening under blue light. Plant Cell Physiol. 2004, 45, 1798-1808. [CrossRef]

51. Ishikawa, R.; Shinomura, T.; Takano, M.; Shimamoto, K. Phytochrome dependent quantitative control of Hd3a transcription is the basis of the night break effect in rice flowering. Genes Genet. Syst. 2009, 84, 179-184. [CrossRef]

Publisher's Note: MDPI stays neutral with regard to jurisdictional claims in published maps and institutional affiliations.

(C) 2020 by the authors. Licensee MDPI, Basel, Switzerland. This article is an open access article distributed under the terms and conditions of the Creative Commons Attribution (CC BY) license (http://creativecommons.org/licenses/by/4.0/). 